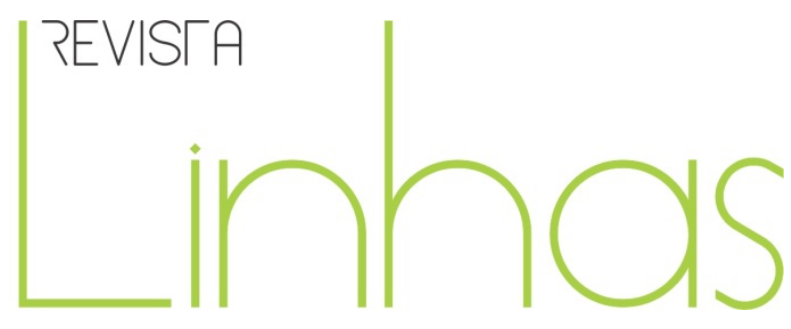

\title{
O elo de veneração: o velho e o novo nos quadros de formatura
}

\section{Resumo}

Este texto se propõe analisar dois quadros de formatura do Curso Normal construídos durante a década de 1920, pertencentes à coleção do acervo do Colégio Coração de Jesus, localizado na cidade de Florianópolis, capital do Estado de Santa Catarina. Além da análise serão apresentadas algumas reflexões teóricas e discussões dos autores que estudam temas correspondentes. A análise desses artefatos se inscreve na perspectiva da cultura material escolar que permite estudá-los como portadores de vestígios ou intenções de verdade que possam trazer à tona as vivências e práticas cotidianas da educação escolarizada. Nos quadros de formatura analisados aqui é possível encontrar uma convivência intrigante entre elementos do universo fotográfico e da arte pictórica. Estas composições, predominantemente imagéticas podem revelar nuances do investimento político, institucional e pessoal engendrados pela efervescência da construção social de necessidades e crenças na formação através da educação. São componentes de uma trama de relações da tessitura social constituída por seus produtores e consumidores que, em contato com eles, deram sentido mútuo as suas existências no universo de uma escola pulsante, de saberes e práticas vividas, sentidas e reproduzidas.

Palavras-chave: Educação; Santa Catarina; História; Colégio Coração de Jesus (Florianópolis, SC); Fotografia.
Nelson Maurílio Coelho Junior

Doutorando em Educação pela

Universidade do Estado de Santa

Catarina - UDESC - Brasil nelsonmacjr@yahoo.com.br

\section{Para citar este artigo:}

COELHO JUNIOR, Nelson Maurílio. O elo de veneração: o velho e o novo nos quadros de formatura. Revista Linhas. Florianópolis, v. 16, n. 30, p. 122 - 151, jan./abr. 2015. 


\title{
The link of veneration: the old and the new in the graduation frames
}

\begin{abstract}
This text aims to analyze two graduation frames of Curso Normal built during the 1920s, from the collection of the library of the Colégio Coração de Jesus, located in the city of Florianópolis, capital of State of Santa Catarina. In addition to analyzing some theoretical reflections and discussions of authors who study relevant topics will be presented. The analysis of these artifacts in the perspective of school material culture that allows studying them as having intentions or traces of truth that can bring out the experiences and daily practices of school education. In the graduation frames discussed here is possible to find puzzling coexistence of elements of the photographic universe and pictorial art. These compositions, predominant imagery can reveal nuances of the political, institutional and personal investment effervescence engendered by the social construction of needs and beliefs in formation through education. Are components of a web of relations of social fabric constituted by its producers and consumers in touch with them, gave mutual sense their existence in the universe of a pulsating school, knowledge and practices experienced, felt and played.
\end{abstract}

Keywords: Education; Santa Catarina; History; Colégio Coração de Jesus (Florianópolis, SC); Photography. 
Dentre os vários componentes materiais que constituem a escola e sua cultura estão os quadros de formatura, objetos aqui concebidos como um dos elementos constitutivos da cultura escolar. Este texto dispõe-se a situar tais objetos sob a perspectiva da reflexão teórica e sistematizar as discussões dos autores que estudam temas correspondentes, articulando discussões do campo da cultura material da escola. Como referência empírica será apresentada uma análise de dois quadros de formatura (1922 e 1926), preservados entre os objetos do acervo do Colégio Coração de Jesus (CCJ), cotejada com dados da história da educação catarinense.

O antigo CCJ, hoje Colégio Bom Jesus (desde que foi adquirido pela ordem dos padres franciscanos em 2006), localiza-se na cidade de Florianópolis, capital de Santa Catarina. Os quadros analisados neste texto são os primeiros quadros produzidos pela instituição e balizam o início de uma trajetória ascendente da instituição no campo educacional catarinense. Ademais, a década de 1920 foi um período de expectativas institucionais e ebulições educacionais. Trata-se do decênio em que a Congregação da Divina Providência - instalada na cidade de Florianópolis desde 1898 - vivenciou o reconhecimento estatal de seu investimento como instituição educacional católica e formadora de professoras no estado de Santa Catarina. Além disso, esse período foi marcado pelas reformas urbanas e pelas promessas de modernização propagandeadas pelo republicanismo. Do ponto de vista educacional, durante essa década foram gestadas as experiências educacionais que desencadearam o movimento da Escola Nova na década seguinte.

Este texto pretende explorar as condições de produção desse material considerandoo como manifestação na dimensão da cultura material escolar. De acordo com Rosa F. de Souza, (2007) a cultura material escolar é composta por

artefatos e contextos materiais relacionados à educação escolarizada, a expressão não apenas amplia o seu significado reinserindo as edificações, mobiliário, os materiais didáticos, os recursos audiovisuais, e até mesmo as chamadas novas tecnologias do ensino, como também remete à intrínseca relação que os objetos guardam com a produção de sentidos e com a problemática da produção e reprodução social. (SOUZA, 2007, 170) 
Para a autora, a expressão "cultura material escolar" deriva, entre outros fatores, dos estudos centrados na cultura escolar, enriquecidos pela ampliação do horizonte dos documentos proporcionada pela História Cultural, e do empenho de historiadores em preservá-los e problematizá-los. Ou seja, o estudo da cultura material escolar possibilita a análise dos objetos e seus efeitos nos usos e desusos no cotidiano escolar. Além disso, possibilita a investigação da circulação dos objetos para a compreensão da escola como um dos espaços privilegiados do circuito comercial da economia capitalista e a expansão da escolarização das massas.

Outros autores também discutem o universo dos objetos que constituem o cotidiano da escola. Os estudos de Martin (2006) sinalizam para as novas tendências historiográficas e seu enorme leque de possibilidades de pesquisa etnográfica e micro histórica para a compreensão crítica da história da educação. Para o autor, a escola é compreendida como um microespaço social construído como uma cultura própria. Esta cultura própria é composta de uma trama de normas, saberes teóricos e práticas pedagógicas inter-relacionadas entre si, que pode ser entendida como cultura escolar. Compreender esta trama contribui para conhecer a "escuela por dentro", assim como suas resistências, aspirações e trocas com o mundo exterior apresentando-se como um dos principais desafios dos historiadores da educação. Dentro desta perspectiva de investigação, os elementos materiais como: o edifício, o mobiliário, o material de ensino, materiais didáticos impressos, lúdicos, decoração entre outros, têm despertado profundo interesse de pesquisa. $O$ autor examinou o período histórico espanhol durante a transição do modelo arcaico de escola para o modernizado dotado de utensílios técnicos avançados, entende que "la arqueologia material de la escuela puede mostrar, a este respecto, los usos y desusos de unos y otros útiles." Martín (2006, p. 286). A ampliação da variedade do material da escola primária está inserida no bojo da consolidação dos estados nacionais e do avanço da industrialização. Souza (2007), já mencionada anteriormente, em seus estudos sobre o assunto, percebe a proliferação dos objetos de uso escolar e chama a atenção para as possibilidades de análise da circulação dos objetos para a compreensão da escola enquanto espaço privilegiado de circulação de mercadorias. A passagem do século XIX para o século XX foi marcada pelos avanços da 
economia capitalista e pela expansão da escolarização das massas. A autora descreve que o significado do estudo da cultura material e sua finalidade da história enquanto ciência

é restituir o passado focalizando as mudanças e as transformações e, assim procedendo, possibilitar aos educadores relativizarem as ideias e propostas educativas, estimular a atitude crítica e reflexiva e permitir perceber a educação como uma construção social, então, a questão é saber o papel desempenhado pelos materiais nos processos educacionais. (SOUZA, 2007, p.174)

Na concepção de pesquisadores como Mignot (2002 p. 51), os objetos escolares, são entendidos como detentores de subjetividade, “[...] Não são testemunhos incontestes. São pistas de formas de ver o mundo [...]". Ainda de acordo com a autora, os trabalhos de pesquisa com os objetos-relíquia “[...] apontam para um processo resultante de interações entre diferentes universos, pontuado por incertezas, balizado por diversos contextos sociais, exigindo alinhavar múltiplos espaços de vida". Longe de serem interpretados como fontes incontestes, os objetos escolares devem ser interpretados como novas possibilidades para a compreensão crítica da história da educação.

Para Moraes (2009), a pesquisa dos objetos da escola pode contribuir tanto para a preservação da memória da instituição, quanto para a ampliação das fontes de pesquisa. Os estudos de Veiga (2000, p. 4), remetem à escola enquanto, “[...] espaço de institucionalização do saber, de produção e transmissão de cultura, hábitos e valores, consolida-se, entre outros fatores, pela importância que teve na ressignificação da cultura material mais geral das sociedades [...]". A presença da cultura material escolar pode ser considerada como indissociável da história da formação docente. Os materiais escolares foram vitais para a concretização da prática pedagógica, estiveram presentes em seus sucessos, fracassos, modernização, transformação, confundindo-se com os modelos de educação concebidos ontem e hoje.

Os estudos que se propõem analisar quadros de formatura ainda carecem de mais produção bibliográfica, sendo a análise de Werle (2006), a mais reconhecida já publicada sobre o assunto. A autora desenvolveu sua pesquisa através da análise dos quadros de formatura, confeccionados no início do século XX, em dois colégios masculinos e duas 
escolas femininas do Rio Grande do Sul. As pesquisas de Schwartzman et al (2001) também merecem atenção pelo fato de explorarem como estes suportes podem resguardar em suas composições imagéticas, as representações sociais de contexto que os materializou. Os estudos de Marinho (2002) iniciam a partir do encontro do autor com um quadro de formatura. Segundo ele, esses suportes reservam um ambiente ímpar de imagens do passado, que podem ser analisadas a partir de aproximações com a arte pictórica. Outros autores não estudaram especificamente os quadros de formatura, mas adentraram em universos de pesquisa correlatos ao tema. Martinez \& Fagundes (2010), por exemplo, dedicaram suas pesquisas à análise do acervo de documentos pertencentes ao Liceu de Humanidades, Escola Normal e a Escola Modelo de Campos. Estudos sobre fotografias de formatura foram desenvolvidos nos trabalhos de Porto e Santos (2009), que dedicaram parte de sua pesquisa às formaturas das escolas de enfermagem, localizadas na cidade do Rio de Janeiro, nos primeiros anos da década de vinte do século passado; Martiarena e Oliveira (2011), que se dedicaram à análise das imagens das professoras em instituições de ensino do município de Pelotas entre os anos de 1920 e 1960; Ribeiro (2007) que analisa as fotografias do acervo do Instituto Feminino da Bahia. A análise de fotografias no cotidiano escolar também pode ser encontrada nos estudos de Rocha (2006) e revelam as representações produzidas pelas fotografias escolares que hoje estão guardadas no Arquivo Público de Uberlândia/MG. Melo e Alves (2011), elaboraram uma investigação sobre as representações e práticas de leitura das normalistas do Instituto de Educação Rui Barbosa entre as décadas de 60 e 70 do século passado. Na análise dos objetos do cotidiano escolar, Fiscarelli (2006) dedicou atenção especial aos troféus de uma escola pública da cidade de Araraquara, no estado de São Paulo; A. C. V. Mota (2009) analisou as transformações ocorridas no campo profissional da medicina, partir dos álbuns de formatura, e convida o leitor para um exercício de interpretação a partir da produção iconográfica que registrou essas transformações; Abreu (1996) analisou os objetos que pertenceram a Miguel Calmon e foram doados por sua viúva ao Museu Histórico Nacional do Rio de Janeiro; Sousa (2007), ao elaborar uma retrospectiva histórica da cidade de Picos no Piauí, tentou compreender as forças que colaboraram para a emergência do ensino secundário na região e entrou em contato com uma série de elementos presentes nos primeiros anos do Ginásio Estadual Picoense; os estudos de Ribeiro e Gaspar (2012) sobre os uniformes escolares também foram 
abordados como documentos de pesquisa histórica e elementos da materialidade do cotidiano escolar e foram analisados como componentes/objetos da cultura escolar.

As pesquisas envolvendo quadros de formaturas demonstram a existência de uma circulação comercial ampliada desses objetos. Desse modo, é possível constatar que os quadros não são invenções do $\mathrm{CCJ}$, pois foram projetados, construídos e consumidos em outras instituições de ensino em diferentes contextos. Essa replicação oferece uma oportunidade para investigações futuras, que podem contribuir para a ampliação da análise aqui proposta.

Ao todo, o CCJ preservou em seu acervo de objetos depositados no sótão, 20 quadros de formatura, 16 de tamanho grande, destinados à exposição nas paredes da instituição, e 4 de tamanho menor ou de mesa. Do montante dos quadros de porte grande, seis deles foram construídos durante a década de vinte (1922, 1923, 1926, 1927, 1928 e 1929). Em dois desses quadros produzidos nos anos de 1922 (Figura 1) e 1926 (Figura 2) ficaram registradas as assinaturas que sinalizam para uma suposta autoria. 0 desejo autoral pode fornecer pistas para a investigação da produção, circulação e consumo desses objetos mercadorias. Seriam essas assinaturas marcas que agregariam valor aos quadros de formatura ou os quadros de formatura do colégio transferiam valor aos autores escolhidos para sua construção? Quem eram esses autores? O que essas autorias poderiam revelar sobre o circuito comercial que envolvia a construção dessas estruturas? Além disso, essas assinaturas despertam o sugerem um trabalho artístico que une fotografia e arte pictórica. Porque a opção por uma representação mista de coleção fotográfica e arte pictórica? Quais os significados da fotografia para a sociedade que os gestou? As respostas para essas perguntas exigirão um deslocamento para o passado, mais exatamente para a emergência da fotografia na cidade de Florianópolis na segunda metade do século XIX, na tentativa de detectar, as possíveis permanências ou ausências representadas nos quadros. 


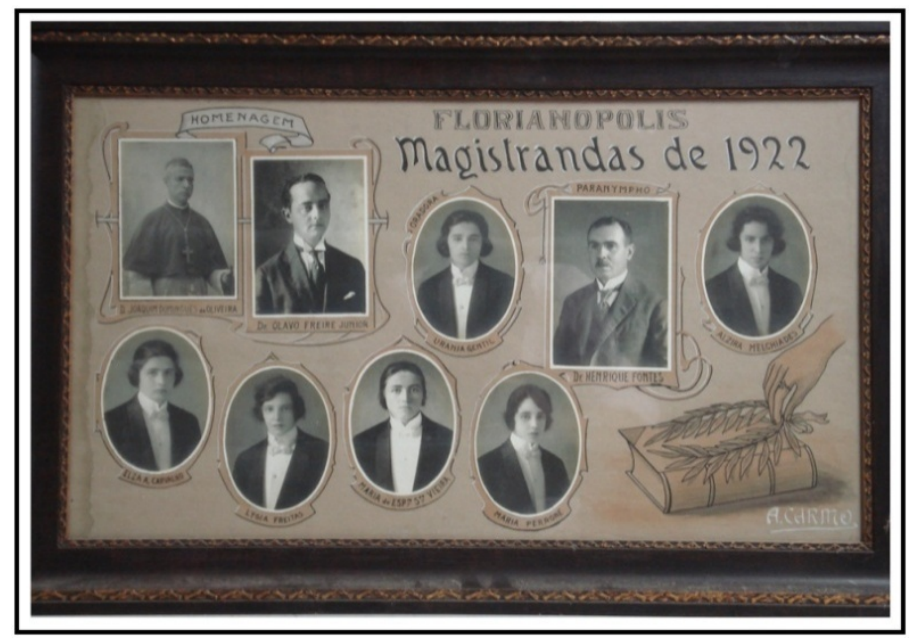

Figura 1 - Quadro de formatura de 1922

Acervo do Colégio Bom Jesus (antigo Colégio Coração de Jesus) Dimensão: $47 \mathrm{~cm} . \times 75 \mathrm{~cm}$

Fotografia do acervo do autor (2011)

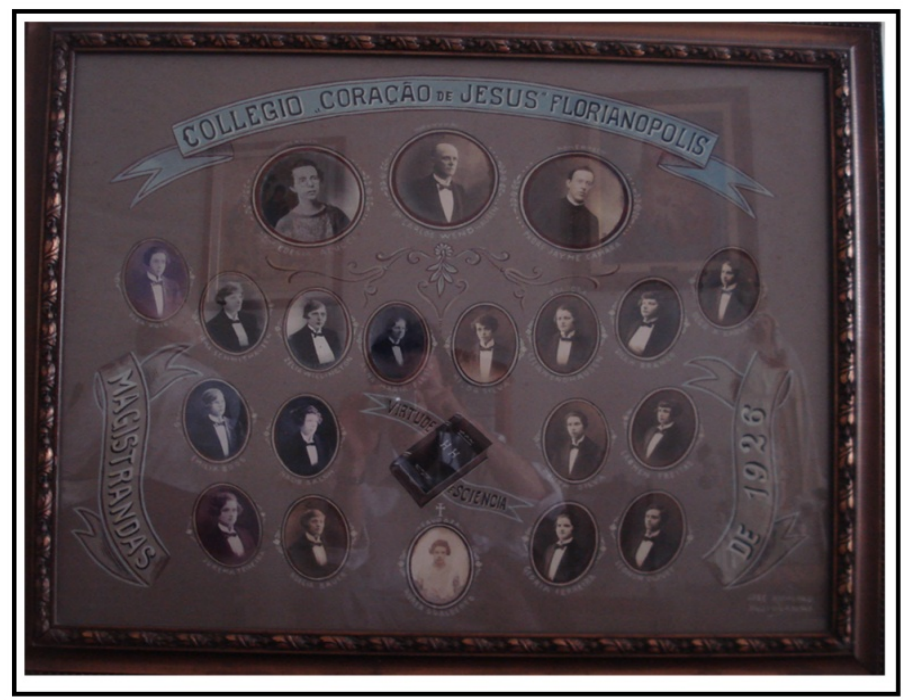

Figura 2 - Quadro de formatura de 1926

Acervo do Colégio Bom Jesus (antigo Colégio Coração de Jesus)

Dimensão: $47 \mathrm{~cm}$. X $75 \mathrm{~cm}$

Fotografia do acervo do autor (2011)

Os quadros de formatura preservaram em seu enredo imagético o convívio aparentemente simbiótico entre a tradição do passado pictórico e a presença marcante da fotografia. O século XX aderiu às representações cênicas da imagem fotográfica que, por sua vez, traziam em seu cerne a presença de antigas regras da tradição pictórica. Retratos opacos do mundo social que os concebeu, os quadros de formatura parecem 
vacilar entre o velho e o novo. A Segunda Revolução Industrial acelerou a produção de mercadorias, fomentou novas tecnologias e expandiu as trocas comerciais. Nesse movimento acelerado de circulação de mercadorias, as fotografias povoavam o imaginário da época com promessas de reconhecimento e perenização. Os estudos de Borges (2003) descrevem que a fotografia era interpretada como o triunfo da humanidade sobre a natureza, pois poderia aprisioná-la apenas com o movimento de um dedo e torná-la eterna. Outros viam a fotografia como uma inovação técnica que causaria mudanças inevitáveis no universo artístico alterando a forma de expressar a realidade em volta. Segundo a autora, "desde cedo o retrato fotográfico se coloca como uma prova material da existência humana, além de alimentar a memória individual e coletiva de homens públicos e de grupos sociais" (Borges, 2003, p. 41).

As fotografias, elementos centrais nos quadros de formatura, podem ser interpretadas na perspectiva de indiciárias do processo de inclusão da cidade na era dos estúdios fotográficos; sinalizadoras de uma provável abertura da sociedade florianopolitana para novos hábitos e gostos; evidências da democratização do consumo da imagem e a consequente legitimação social dos fotógrafos e seus novos negócios ligados ao universo fotográfico.

A República trouxe consigo as promessas de modernização que caminhavam a passos lentos. Como o gelado vento sul, característico dos meses de inverno em Florianópolis, os discursos não tardaram em sacudir as portas da capital catarinense, que aos poucos se entregavam às propostas promovidas pelo ideário burguês positivista carregado de discursos higienistas e progressistas. Assim como na capital federal, o centro da cidade de Florianópolis se transformou em um canteiro de reformas e demolições. Nesse contexto de transição, frustração e inovação, emergem os quadros de formatura no início da década de 20. Essas estruturas de exposição, por suas características físicas captadas, sem muita dificuldade pelo observador, como molduras, desenhos, pinturas, cores, adornos, rococós e assinaturas remetem a um trabalho impregnado de prescrições estéticas tradicionalmente utilizadas por artistas plásticos.

Um registro da atividade desses profissionais na cidade de Florianópolis foi encontrado no jornal República publicado no dia 5 de janeiro de 1922. Nele o fotógrafo Arthur Carmo - autor que assina o segundo quadro de formatura construído no CCJ no 
ano de 1922 -, divulga seu trabalho através de um anúncio veiculado na seção de classificados (Figura 3). O texto do anúncio expõe que - apesar das facilidades proporcionadas pelo refinamento tecnológico da reprodução de instantâneos, desde o advento da Kodak, nos fins do século XIX -, Arthur Carmo permanecia na tradição dos primeiros retratistas que aportaram na cidade de Florianópolis a partir da segunda metade do século XIX.

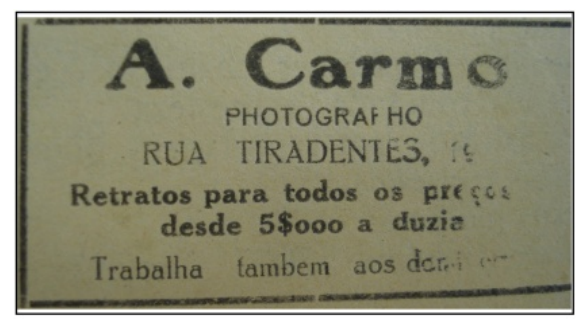

Figura 3 - Jornal República de 05 de janeiro de 1922

Arquivo de Periódicos da Biblioteca do Estado de Santa Catarina Fotografia do acervo do autor (2011)

Nesse anúncio é possível perceber que o comerciante buscou enfatizar as facilidades de aquisição pela variedade dos preços e pela quantidade de fotografias que poderiam ser adquiridas em todos os dias da semana no seu estabelecimento localizado na Rua Tiradentes. Essa rua localiza-se no centro da cidade e está a menos de 500 metros de distância do Colégio Coração de Jesus. De acordo com Borges (2003), já citada anteriormente, a fotografia figurava, nas primeiras décadas do século XX, como uma inovação, que se tornava mais acessível economicamente à medida que as novas tecnologias barateavam o custo e proporcionavam a ampliação do consumo. Trata-se de uma etapa de expansão comercial da atividade de fotógrafo e

imediatamente inicia-se uma democratização dos valores dos signos fotográficos. Os anúncios em jornais divulgavam o endereço do novo profissional da fotografia, bem como o raio de extensão de sua produção. Como pequenas fábricas de ilusão, seus estúdios atraíam homens e mulheres, que individualmente ou em grupos, davam vazão às suas fantasias. Para tal os estúdios ofereciam uma variedade de apetrechos utilizados na montagem de cenários de acordo como o desejo de autorrepresentação de seu público. (BORGES, 2003, p. 51) 
A expansão dos negócios ligados à fotografia na cidade de Florianópolis fica mais evidente no anúncio veiculado pelo jornal República, no dia 06 de novembro de 1927, pelo fotógrafo José Ruhland (Figura 4). Nesse anúncio, o autor divulga na seção de classificados do jornal que seu estabelecimento oferece

\begin{abstract}
o mais belo presente que v. s. pode offerecer a seus filhos e amigos no anniversário ou Natal é um aparelho photographico. Apparelhos desde $18 \$ 000$ das marcas Kodak - Contessa - Ernemann - Goerz - Ica, etc, etc. Instrução gratuita aos srs. Compradores. Sortimento completo de artigos para Profissionaes \& Amadores: Films, Film-packs, Chapas, Papeis, Cartões, Albuns, Produtos chimicos, e todos os Accessorios para photographia das melhores Fábricas: Agfa, Satrap, Kodak, Leornar, Gevaert, etc. etc. Execução rápida e perfeita de qualquer trabalho para os srs. Amadores.
\end{abstract}

A loja oferece inúmeras opções de presentes ligados ao universo fotográfico e fornece algumas pistas sobre a demanda para esse tipo de produto na cidade. O que chama a atenção é que, mesmo com a facilitação de acesso a essas mercadorias, a figura do profissional da fotografia é preservada, em uma provável intenção de agregar prestígio à empresa através da competência profissional do proprietário. A presença de marcas estrangeiras no anúncio dos equipamentos indica a inserção da cidade no circuito de circulação e consumo do comércio internacional de mercadorias. Vale destacar a localização do comércio intitulado de "Casa José Ruhland, Photographo, Rua Conselheiro Mafra 124". Assim como o estabelecimento comercial de Arthur Carmo, a Casa José Ruhland se localizava no centro da cidade a aproximadamente meio quilômetro do CCJ. Os empresários abriram seus estabelecimentos comerciais na área central da cidade e nas proximidades do colégio. Esta aproximação, inicialmente geográfica, assinala para uma possível tática de acesso que contribuiu decisivamente para a materialização dos quadros de formatura. 


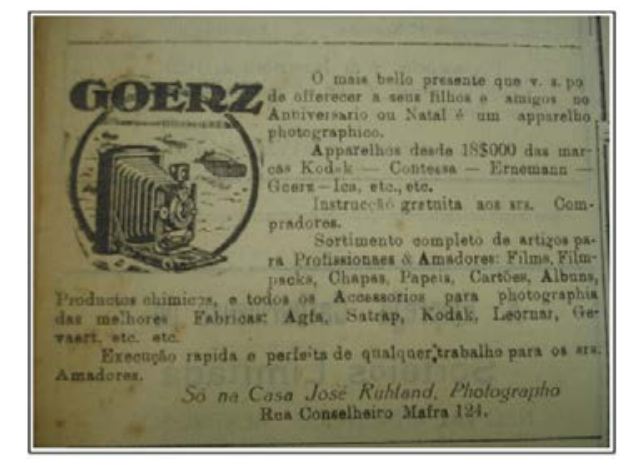

Figura 4 - Jornal República de 06 de novembro de 1927

Arquivo de Periódicos da Biblioteca do Estado de Santa Catarina Fotografia do acervo do autor (2011)

$\mathrm{O}$ ato de consumir artigos ligados ao universo fotográfico, assim como pagar pelo ensino, ainda era restrito a um reduzido número de consumidores. O CCJ foi fundado pelas irmãs da Congregação da Divina Providência com o objetivo de formar as filhas provenientes majoritariamente das famílias com um poder aquisitivo mais elevado no Estado de Santa Catarina. Autores como Leal \& Cunha (1991), descrevem que a emergência do Colégio Coração de Jesus na cidade de Florianópolis, no período de transição do século XIX para o século XX representou uma possível solução para as defasagens da época. A instituição preenchia uma lacuna no processo de formação das meninas das classes mais abastadas e o ensino oferecido era limitado aos que podiam pagar. De acordo com as autoras, o colégio se propunha a formar as filhas dos poucos privilegiados membros de uma "classe média que passava a ocupar postos, seja na burocracia federal ou estatal que se formava, seja no comércio ou em outras atividades econômicas que aos poucos se diversificavam, colocavam necessidades novas, como as relacionadas à educação dos filhos" (LEAL e CUNHA, 1991, p. 37).

\section{"O artista-photographo"}

O sucesso da fotografia no início do século passado estimulava a criação de novidades técnicas que barateavam o seu consumo e expandiam os negócios ligados à reprodução da imagem na cidade de Florianópolis. Na Europa, a emergência da fotografia causou inúmeros debates em torno de sua utilização como representação da realidade e muitos fotógrafos negavam-se a concebê-la como mero suporte de reprodução técnica. Não foram poucos os fotógrafos que se apropriaram de técnicas imanentes ao mundo 
das artes plásticas para trabalhar essa inovação moderna. Os estudos de Borges (2003), já citada anteriormente, sobre os debates que colocavam a fotografia em um campo de confronto entre arte e técnica levou à transformação de muitos estúdios, onde os artistas se reuniam, criavam e se confraternizavam a realizar experiências com a fotografia. Esses estúdios híbridos, na maioria das vezes eram conduzidos por artistas marginalizados ou seduzidos pelas inúmeras possibilidades da fotografia.

Em 1854, portanto quinze anos depois do reconhecimento oficial do daguerreótipo, o caricaturista, desenhista e escritor Gaspard-Felix Tournachon, conhecido como Nadar (1820-1910), inaugura, no número 113 da rua Saint-Lazare em Paris, um atelier de retratos fotográficos. Imediatamente, o estúdio desse membro da burguesia da capital francesa torna-se um lugar privilegiado de reunião da elite artística, intelectual e científica parisiense e estrangeira. (Borges, 2003, p. 41)

As técnicas de perspectiva se amalgamaram no trabalho de tratamento das imagens fotográficas em um aparente esforço para conciliar modernidade e tradição. Mais do que apenas uma opção estética, a inclusão das técnicas do universo pictórico no tratamento da imagem fotográfica pode ser interpretada como a busca por legitimá-la como objeto de adoração e admiração. Esses artistas estavam em uma nova trincheira para alcançar aceitação e reconhecimento. Tudo leva a crer que não eram tão ingênuos como às vezes são apresentados na literatura, e atuavam de forma deliberada para conquistar seu espaço no campo detentor das regras e prescrições. Essa tendência de conciliar a fotografia com a arte emerge em Florianópolis através de um anúncio, cujo título “Exposição de Retatos”, datado de 02 de abril de 1922 (Figura 5), foi publicado no jornal República e divulgado que

O apreciado artista-photographo sr. Arthur Carmo fez, hontem, nas montras de seu atelier, á rua Tiradentes, uma exposição de artísticos trabalhos - retratos de distinctas senhoras e senhoritas do nosso meio. São provas do grande merecimento do talentoso artista que tanto se recommenda ao apreço público.

A nota no jornal intenciona vincular Arthur Carmo com a imagem de artista. O enlace se consolida no anúncio e a exposição de "retratos de distinctas senhoras e 
senhoritas" da sociedade florianopolitana sugere ao leitor o conhecimento e o reconhecimento público de sua posição como "artista-photographo". O profissional parece buscar construir uma imagem vinculada a uma categoria antiga de profissionais envoltos por uma aura de reconhecimento de valor estético e cultural. Agregar essas qualidades emprestaria distinção social e, consequentemente, econômica ao artista e aos consumidores de suas obras.

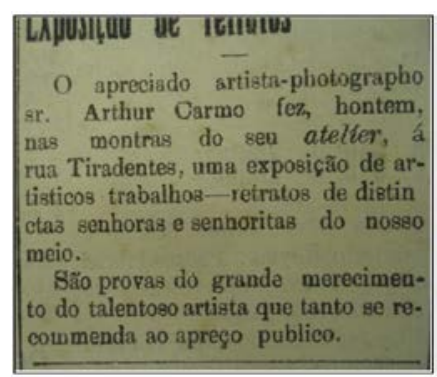

Figura 5 - Jornal República de 02 de abril de 1922

Arquivo de Periódicos da Biblioteca do Estado de Santa Catarina Fotografia do acervo do autor (2011)

Sua biografia foi alterada pela indexação da aura de artesão especializado e livre, uma vez que podia controlar o meio de produção que o sustentava. Sua apresentação social como um artista e expositor - divulgada no informe -, propõe uma construção biográfica que possa lhe conferir uma aura especial do "talentoso artista que tanto se recomenda ao apreço publico". Arthur Carmo encontra-se de acordo com os estudos Freund (2011) na segunda época do estilo fotográfico, quando os fotógrafos se viram obrigados a adaptar seu ofício ao gosto de um público mais seleto. Ser reconhecido como um artista agregava valor e distinção ao seu trabalho, distinção essa devolvida através do reconhecimento social pela capacidade de consumo dessa insígnia de sucesso social restrita a poucos escolhidos. Será possível então, verificar como essa tentativa de reconhecimento e distinção se manifestou nos quadros de formatura produzidos por esses artistas-fotógrafos no Colégio Coração de Jesus?

Par tentar responder esta pergunta será necessário, antes de tudo, buscar como se deu a aproximação desses artistas com o CCJ. A construção dos quadros de formatura fazia parte de uma lógica mercadológica que envolvia o reconhecimento do construtor no mercado da fotografia e das artes. Os anúncios nos jornais divulgavam os serviços 
fotográficos do autor, distinguiam o produto (fotografia e seus derivados), tornando-os valorizados e reconhecidos no mercado das imagens. Os preços ainda elevados para os padrões locais restringiam o consumo e conferiam distinção aos privilegiados que podiam consumi-los. Tanto o Colégio Coração de Jesus, quanto os artistas-fotógrafos, faziam uso dos jornais para divulgar seus serviços no início da década de vinte. O jornal República, publicado em 05 de fevereiro de 1922 (Figura 6), oferece uma amostra do convívio comercial entre Colégio e fotógrafos. Sem descartar a possibilidade do mero acaso, a proximidade dos anúncios do Colégio e do fotógrafo são indícios tentadores e alvitram para uma convivência semeada nas grades da tipografia e colhida nas entrelinhas dos quadros de formatura.

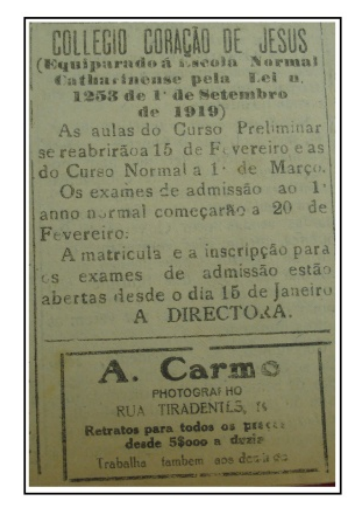

Figura 6 - Jornal República de 05 de fevereiro de 1922

Arquivo de Periódicos da Biblioteca do Estado de Santa Catarina Fotografia do acervo do autor (2011)

Aqui, é possível verificar a importância do reconhecimento da instituição no campo educacional através da regulamentação estatal. Envolto por um clima de instabilidade e expectativas frustradas no campo educacional, o Colégio Coração de Jesus emergiu na transição do século XIX para o século XX com ambições que iam além da educação de alunos. A demanda pela formação de professores abriu uma oportunidade para as irmãs da Congregação da Divina Providência, na direção de formar mulheres normalistas. Fundado em 15 de janeiro de 1898, no centro da cidade sobre uma colina que destacava sua imponente arquitetura, o colégio ganhou fama e prestígio. No ano de 1908, através do Decreto $n^{\circ} 348$, do governador Gustavo Richard, o CCJ recebeu a autorização para a abertura de um curso preparatório para alunas que desejavam ingressar na Escola Normal na cidade de Florianópolis; Em 1911, foi criada a escola complementar autorizada pelo Decreto $n^{\circ} 604$, de 11 de julho, durante a administração do governador Vidal Ramos; 
Em 1914, através da Lei $n^{\circ}$ 1025, de 14 de outubro, o colégio recebeu a designação de escola complementar equiparada à Escola Normal Catharinense ${ }^{1}$, através da publicação da Lei $n^{\circ} 1253$, de $1^{\circ}$ de setembro de 1919, a que se refere o Decreto $n^{\circ} 1340$, de 20 de fevereiro. De acordo com esse decreto, a Escola Normal, anexa ao Colégio Coração de Jesus deveria reger seu programa em igual regime de matrícula, de aulas e de exames. A lei divulgada no anúncio do jornal marca uma relevante conquista institucional, pois expressa o reconhecimento político do trabalho de formação de normalistas no Estado de Santa Catarina.

Ao estudar os centros de formação docente, o pesquisador português Nóvoa (1991) diz que a passagem do século XIX para o século XX, demarca a passagem do antigo para o novo, do mestre-escola para o professor primário. Afirma o autor que estes centros de formação

ocupam um lugar central na produção e reprodução do corpo de saberes e do sistema de normas da profissão docente, desempenhando um papel crucial na elaboração dos conhecimentos pedagógicos e de uma ideologia comum. Mais do que formar professores (a titulo individual), as escolas normais produzem a profissão docente (a nível coletivo), contribuindo para a socialização dos seus membros e para a génese de uma cultura profissional. (NÓVOA, 1991, p.18)

No universo dos centros de formação de professores, pautado pela inépcia estatal de superar antigas tradições e práticas, o colégio buscou oferecer um ensino diferenciado e em sintonia com o desejo das classes abastadas. Equiparado à Escola Normal, o colégio tinha que obedecer a base curricular prescrita pelo governo do Estado, mas não era impedido de acrescentar disciplinas complementares. Desta feita, o colégio desenvolvia um currículo próprio alicerçado na moral católica e no controle rígido de condutas e comportamentos. A vigilância era constante e as alunas eram submetidas a um processo de formação que lhes impregnava os poros e as mentes, a fim de uniformizar suas atitudes de acordo com as normas da instituição.

\footnotetext{
${ }^{1}$ Criada em 10 de junho de 1892, através do Decreto n. 155, no Governo do Tenente Manoel Joaquim Machado.
} 
Vale lembrar que a graduação das primeiras turmas do Colégio Coração de Jesus aponta para trabalho de formação que não se restringia apenas ao aspecto docente, pois muitas dessas alunas não se dedicariam mais tarde ao ofício de professora. A maternagem também era, segundo Cunha (2003, p. 205), um dos objetivos formadores das alunas. Para essa autora o

Colégio Coração de Jesus, tinha como função essencial a formação da 'mulher de bem', calcada nos princípios da moral católica, onde ser aluna desse Colégio representava um meio tradicional de preparo dessas moças para assumirem as funções de esposa, dona de casa e mãe que Ihes estavam reservadas e, no limite, exercerem o magistério como sacerdócio e como uma forma de maternagem simbólica.

As formaturas da década de vinte do século passado gestaram uma prática social envolta em rituais que primavam, sobremaneira, pela espetacularização de um evento que deveria celebrar a conquista de uma posição distinta do ponto de vista social, reforçando a posição de determinado grupo no campo social. Os jornais, de acordo com Motta (2002), atuavam como veículos que não se limitavam apenas ao circuito comercial, sua abrangência atingia outras instâncias de ação, pois

Não existe imprensa sem inserção política. A política não é a única instância de ação da imprensa. Ela desempenha igualmente funções econômicas, especialmente comerciais, quando estimula, por meio dos seus anúncios, o consumo de bens. Da mesma forma, ela tem um papel cultural na medida em que veicula e consolida hábitos, costumes, gostos. Possui ainda, um papel jurídico-institucional, como legitimadora de regras éticas e morais socialmente aceitas. (MOTTA, 2002. p. 15)

Os anúncios jornalísticos do colégio operavam como um reforço de fazer circular uma imagem de solidez na formação de professores, a lei que equiparava o colégio à escola normal pode estar inserida no anúncio como uma forma de apresentar ao público uma instituição, cujo trabalho era reconhecido através do Estado e suas prerrogativas legais. O poder não aparece, nesse caso, como uma forma de dominação ou prescrição opressiva. Sua manifestação através da legislação oferece a validação necessária para que 
uma parcela da sociedade, leitora de jornais, possa ver, ler e distinguir a instituição de ensino como portadora de condições de formar normalistas.

A circulação de ideias através do jornal indica uma rede de trocas sociais, que pressupõe a construção de verdades e gostos por meio desse veículo de comunicação. Para Arthur Carmo, a notícia sobre o colégio parece ter oferecido algumas oportunidades. Os anúncios indicam um movimento de aproximação entre o trabalho do fotógrafo e a instituição de ensino. Supõe-se, através dessa ação uma intenção de estimular, por meio dos seus anúncios, o consumo das fotografias e talvez, consolidá-las como hábito, costume e gosto dos leitores do jornal. Desse modo, é possível verificar como colégio e fotógrafo faziam uso da imprensa para divulgar, valorizar e reforçar a adoção de hábitos, costumes e gostos.

O anúncio do colégio era seguido logo abaixo pelo anúncio do fotógrafo que assinou o quadro de formatura de 1922. Parece se tratar de uma estratégia de publicidade bem sucedida de vincular o colégio ao fotógrafo que desejava comercializar seu trabalho. Esse fato sinaliza para a emergência desse artefato como fruto de uma construção social dinâmica que envolvia o reconhecimento do público consumidor dos serviços educativos, artísticos e fotográficos. Esse quadro de formatura, portanto, foi elaborado por um trabalho de construção que remete aos estudos de Chartier (1991), em que percebe as materializações de um tempo e lugar sob a perspectiva do conceito de representações. Os objetos podem ser interpretados como frutos de um processo de construção da realidade social por um determinado grupo, obedecendo a critérios de classificações, divisões e delimitações. Esses critérios estão ligados a esquemas intelectuais que através de suas criações e composições dotam o presente de sentido.

O objeto fundamental de uma história que se propõe reconhecer a maneira como os atores sociais dão sentido a suas práticas e a seus enunciados se situa, portanto, na tensão entre, por um lado, as capacidades inventivas dos indivíduos ou das comunidades e, por outro, as restrições e as convenções que limitam - de maneira mais ou menos clara conforme a posição que ocupam nas relações de dominação - o que Ihes é possível pensar, dizer, fazer. [...] essa noção [a de representação] permite vincular estreitamente as posições e as relações sociais com a maneira como os indivíduos e os grupos se percebem e percebem os demais. (CHARTIER, 1991, p. 49) 
A formatura de 1922 foi representada por Arthur Carmo obedecendo a critérios artísticos muito próximos dos verificados na tradição da arte pictórica, e pode oferecer nuances das relações sociais envolvidas em sua produção. A cena da formatura, congelada no quadro pode proporcionar ao espectador uma coreografia de imagens opacas da época de sua materialização. Os artistas-fotógrafos Arthur Carmo e José Ruhland registram nos quadros de formatura vestígios de uma possível interação entre a arte pictórica e a fotografia.

\section{O "artista-photographo" e a cidade}

O quadro de formatura de 1922, construído por Arthur Carmo apresenta uma moldura com as dimensões de $47 \mathrm{~cm} \times 75 \mathrm{~cm}$. A estrutura possui uma largura de $11 \mathrm{~cm}$ em madeira entalhada e acabamento em gesso. A base da estrutura foi construída sobre madeira nobre de cor escura com acabamentos em relevo e na cor dourada nas bordas mais elevadas da extremidade exterior e nas bordas interiores que margeiam a composição. Os relevos internos são constituídos por triângulos com um ponto no centro (que lembram olhos) intercalados por três pontos em triangulação. Os relevos esculpidos nas bordas externas da moldura apresentam pequenos relevos em triangulação que lembram pequenos ossos. A moldura do quadro de 1926, construído por José Ruhland, apresenta uma moldura nas mesmas dimensões do quadro de Arthur Carmo. A madeira também é a imbuia, mas a cor dourada predomina no último, emprestando-lhe mais luminosidade e destaque que o primeiro. Embora coincidam nos aspectos estruturais, as molduras se diferenciam no acabamento, sendo a borda interior da moldura de Ruhland decorada com relevos de folhas e frutos, enquanto a borda exterior é adornada em sua extremidade com pequenas esferas alinhadas.

A presença das molduras denuncia uma estreita ligação entre os quadros de formatura e as obras de arte. Para ter uma melhor compreensão de sua função em uma obra de arte, é possível recorrer aos estudos de Aumont (1993). O autor define a moldura como o limite perceptivo ou a separação entre o que está dentro e o que está fora da obra de arte, tornando-a singularizando- e atribuindo-lhe mais visibilidade. Desempenha ainda o papel de intermediário na observação, retardando a transição do olhar entre o 
que está dentro da cena e o que está fora. Os pintores clássicos foram muito sensíveis a esta função da transição do olhar, principalmente no que diz respeito à utilização da moldura dourada, que permitia banhar a pintura com uma luz amarela.

A moldura, ao delimitar a cena, cria um campo visual, uma janela para o imaginário e lança o observador em um mundo de imagens e alegorias separado do mundo que está fora. Além disso, a moldura organiza as imagens presas em seus limites, dando lógica ao conjunto, que pode ser denominado de composição. A moldura confere à obra de arte um valor econômico; o autor descreve que "o emolduramento, sob a forma que o conhecemos apareceu aproximadamente ao mesmo tempo em que a concepção moderna do quadro como objeto destacável, trocável, que pode circular como mercadoria nos circuitos econômicos" (AUMONT, 1993). Não é de se espantar que os detalhes de cor dourada, semelhante ao ouro, tenham sido utilizados com muita frequência nas molduras antigas. A moldura obriga o leitor visual a adotar uma postura diferenciada ao apreciar uma imagem emoldurada, pois esta lhe diz que o que se observa possui valor e distinção. Aparentemente são pequenos detalhes diluídos na totalidade da composição, mas que materializam intenções forjadas no jogo social e perpetuadas nos limites da composição.

No que diz respeito à disposição e organização das imagens no plano, a análise dos quadros de formatura pode sinalizar para uma intenção proposital ou não de alinhamento obedecendo a supostos esquemas geométricos. No quadro de Arthur Carmo, as fotografias são distribuídas em duas linhas horizontais, com eixos bem marcados. Não há linhas que induzam à ilusão da perspectiva, tampouco movimento interno formando uma composição estática. No quadro de José Ruhland, as fotografias são distribuídas em uma geometria circular. Não há linhas que induzam à ilusão da perspectiva, mas a disposição das fotografias em circulo induz a um movimento conferindo uma dinâmica à composição. Nos dois quadros, o olhar do observador é atraído pela posição, forma e adereços das fotografias das autoridades, que ficam mais evidentes no todo. Não se trata de uma novidade, pois estes artifícios podem ser observados com bastante frequência em composições similares confeccionadas neste período.

Nos dois quadros predominam, no fundo da composição, o papel claro de cor neutra bege no quadro de 1922, e papel um pouco mais escuro de cor neutra, na 
tonalidade berinjela no quadro de 1926. A cor cinza sugere uma neutralidade que não interfira no conteúdo da composição além de lhe conferir um aspecto que remete a uma representação clássica e sóbria. Esta frieza da cor de fundo remete à proposta do CCJ baseada na educação feminina casta e religiosa. Cunha (1991), já citada anteriormente descreve que o colégio exigia a disciplina e as alunas eram preparadas para exercer

pudor, inocência, pureza e modéstia no plano moral (de acordo com o modelo mariano), de recato, contenção, elegância, e 'finos modos' no plano social (de acordo com o modelo de 'autêntica senhora), o colégio atuava, com rigor e aplicação verdadeiramente germânicos, através de práticas disciplinares, notadamente aquelas que tinham por alvo o corpo das alunas. (CUNHA, 1991, p. 66)

De acordo com a autora, o colégio exercia sobre as alunas um rigoroso controle comportamental e corporal derivado do modelo de internato e de convento. A sexualidade era colocada em segundo plano e a fiscalização das prescrições era realizada com tanta rigidez que condicionava o surgimento de uma espécie de disciplina corporal que acompanhava essas alunas por toda a vida. No colégio, essas meninas podiam continuar seus estudos, haja vista, que inexistiam escolas secundárias oficiais às quais tivessem acesso.

No quadro de 1922, no canto inferior direito vê-se o desenho de linhas finas de uma mão feminina delgada com um anel, enquanto que no quadro de 1926, é possível observar um livro de capa preta com as inscrições H. H. sobre uma faixa com os dizeres: “virtude e sciencia". O desenho procura demonstrar um ideal de formação que, como já foi tratado anteriormente, extrapolava a formação de futuras professoras, pois também primava em formar mulheres, esposas e futuras mães de família dentro de uma sólida orientação católica. Os trabalhos com agulha seguiam em paralelo aos estudos científicos e religiosos. O colégio recebia moças provenientes de todo o estado e, por isso, também funcionava no regime de internato. Nos dois quadros é evidente a interferência artística dos construtores; são desenhos, acabamentos, rococós que transmitem ao observador a ideia de movimento da composição e auxiliam na interpretação da mesma através de uma espécie de texto imagético impregnado de simbolismos. 
Outra semelhança visível nos dois quadros é o tratamento artístico dispensado para os contornos que margeiam as fotografias. Assim como a presença de inscrições que funcionam como legendas auxiliares na leitura do quadro. No quadro de 1922, lê-se na parte superior a localização do evento representado: “Florianópolis" em letras de forma, tabuladas em caixa alta na mesma cor do fundo do quadro em seu centro e contornadas em linha de cor preta. Abaixo dessa inscrição, apresenta-se o título da obra: "Magistrandas de 1922" em letras escuras e dimensão um pouco maior que o nome da cidade. No quadro de 1926, a localização foi pintada sobre um emblema em forma de faixa que se desenrola destacando o nome do colégio antes da cidade: "Collegio Coração de Jesus Florianópolis", escrita em letras desenhadas em caixa alta envolvidas por uma faixa azul clara centralizada. Nesse quadro, a lateral esquerda possui dois emblemas: o primeiro em forma de faixa que se desenrola em uma frase: "FORMANDAS" e o segundo, localizado na faixa lateral direita descreve a data: "de 1926". Não resta dúvida sobre as coincidências entre elementos presentes na arte pictórica e nos quadros de formatura e a sua utilização desvenda uma intenção que não se reduz apenas aos critérios meramente estéticos. Este encontro marcado por inovação e permanência se dá em meio às fracassadas tentativas republicanas de livrar-se das permanências do antigo regime. Trata-se de um contexto de encontros entre o passado que insiste em permanecer e um presente ansioso por renovação.

As formaturas da década de vinte do século passado fomentaram uma prática social envolta em rituais que espetacularizavam um evento que deveria celebrar a conquista de uma posição distinta do ponto de vista social. Ao analisar alguns protocolos que envolvem os cerimoniais de formatura no CCJ, Cunha (2012, p. 1) conclui que,

o ritual de uma formatura escolar envolve solenidades de caráter especial tais como a distribuição de convites impressos, ofícios religiosos, cerimônia festiva de colação de grau e entrega de diploma e, muito esperados, os discursos celebratórios tanto dos representantes dos formandos - os oradores - como dos homenageados especiais - os paraninfos. (CUNHA, 2012, p. 1)

A formação das professoras celebrada pela solenidade da formatura do colégio representa o ápice do processo de formação docente, legitimando e coroando as 
aptidões e talentos da instituição, das alunas, das famílias e do Estado. Todo o processo foi legado à posteridade pelos quadros de formatura que cristalizaram em sua superfície uma parcela das tensões que ocorriam no campo educacional no momento de sua emergência. A formatura de normalistas era apresentada como um sopro de esperança sobre a calmaria de ações que pairavam sobre o estado naquele momento e ratificava o investimento na formação de quadros para o magistério.

O elo entre elementos pictóricos e fotográficos parece sinalizar para intenções mais ambiciosas dos idealizadores e construtores dos primeiros quadros de formatura do colégio. A possibilidade de reprodução da fotografia aparentemente não foi suficiente para o seu uso exclusivo nos quadros. A contratação de artistas-fotógrafos sugere que a experiência de reproduzir uma série fotográfica no estúdio não foi - para sociedade florianopolitana da década de 1920 - significativa o bastante para destituir, o artista pictórico e sua criação, de sua aura de autenticidade e unicidade. Esses dois últimos conceitos foram cunhados por Walter Benjamin (1994). Segundo ele, a autenticidade de uma obra de arte reside no reconhecimento que o "aqui e agora" delega à obra considerando não somente suas características físicas, como também sua trajetória até os dias atuais. Já o conceito de unicidade reside no caráter único e tradicional da obra. Sua essência está no valor de culto e de sacralização da obra de arte "o valor único da obra de arte 'autêntica' tem sempre um fundamento teológico, por mais remoto que seja [...]", e ainda "esse modo de ser aurático da obra de arte nunca se destaca completamente de sua função ritual”. (BENJAMIN, 1994, p. 173). Desse modo, a interpretação da construção desses artefatos de formatura pode ser lida como uma tentativa de representar o fato como um evento fora do comum. A utilização de artifícios estéticos típicos das obras de arte induz a crer na existência de um propósito de superação. A superação dos limites físicos da madeira, do vidro e do papel para alcançar uma dimensão imaterial da representação. A fotografia por si só não cumpria o papel de representar o acontecimento. A modernidade se mostrou insuficiente diante da força da tradição. Tradição replicada no campo social e materializada nas permanências que atravancavam o processo de escolarização republicano. 


\section{O "artista-photographo" e sua atuação nos quadros de formatura do Colégio Coração de Jesus}

O trabalho dos artistas-fotógrafos cristalizou uma composição que tem na fotografia seu principal elemento. Os quadros de formatura analisados suportam uma convivência intrigante entre o velho e o novo, o tradicional e a inovação. Desse modo, é possível inferir que a fotografia, durante a década de 1920, na cidade de Florianópolis contava com o reconhecimento social na função de perenizar ou cristalizar um momento. Os estudos de Delory-Momberger (2010) descrevem um início bastante atribulado para a fotografia. Para a autora, esse suporte emerge em um contexto de expectativas de afirmação, reconhecimento e perenização, uma vez que a fotografia oferecia a ilusão da realidade congelada pelo dedo do fotógrafo. Seu apelo como perpetuação do real seduzia e vendia. O quadro de formatura de 1922 é constitú́do de nove fotografias, sendo três de homenageados e seis de formandas. A composição dessas se apresenta em distintos formatos e tamanhos. Os retratos dos homenageados são de formato retangular em tamanho destacado das outras e posicionados na parte superior da representação, o paraninfo: Henrique Fontes, professor, escritor e Diretor da Instrução Pública do Estado de Santa Catarina, Os homenageados: D. Joaquim de Oliveira, arcebispo metropolitano e Olavo Freire Junior, secretário particular do governador e a oradora. As fotos da oradora, Urânia Gentil e Alzira Melchiades também se encontram na parte superior do quadro, mas em formato circular de dimensão menor e similar as das outras formandas. Abaixo estão agrupadas as fotografias das formandas: Dilza A. Carvalho, Lygia Freitas, Maria do Espírito Santo Vieira e Maria Perrone.

A reprodução de critérios de construção parece se repetir durante a década de 1920. Na formatura de 1926, a assinatura do artista se repete. O quadro apresenta um total de 20 fotografias, sendo 3 de homenageados ligeiramente maiores do que as 17 de formandas (uma delas destacada em roupas de cores mais claras presta a homenagem a uma aluna falecida); as fotografias são de formato circular. Nesse quadro é possível verificar permanências presentes na estrutura construída por Arthur Carmo em 1922. As medidas são as mesmas, bem como a quantidade de homenageados, a dimensão diferenciada das fotografias dos homenageados, as inscrições dos nomes dos personagens na parte inferior das fotografias, os rococós e desenhos que contornam os 
retratados, o formato circular das fotografias das formandas, o material e os detalhes do acabamento das molduras, o papel de cor neutra no fundo do quadro e a assinatura do autor da obra no canto inferior direito.

Assim como nos demais quadros construídos em outras instituições, a presença de autoridades políticas sinaliza para a existência de uma rede de sociabilidade construída entre o Colégio Coração de Jesus e o poder representado em diversas esferas como o Diretor da Instrução Pública do Estado de Santa Catarina, o arcebispo metropolitano, o secretário particular do governador e de outras personalidades representadas em fotografias diferenciadas no formato e nas dimensões destacadas no quadro. A presença das autoridades na formatura conferia prestígio ao evento, à instituição e às autoridades. Uma relação de trocas, em que o paraninfo contribuía financeiramente com a solenidade e, ao mesmo tempo, tinha sua imagem associada a um evento significativo no campo social. Dar e receber, e ser associado definitivamente a uma solenidade representada na coleção fotográfica e transcendendo a própria morte, pois o reconhecimento e a consagração das formandas e da instituição transferiam-se também ao paraninfo e aos homenageados. Ao se convidar o paraninfo, toda a sua rede familiar e de trocas sociais era convocada para estreitar laços com a instituição, principalmente no início do primeiro decênio, marcado pelo reconhecimento e pela normatização estatal. O convite feito ao Deputado Carlos Wendhausen - pai de uma das formandas - agregava valor político ao legislador e tinha forte impacto perante a sociedade em geral. Sua presença no topo do quadro de formatura simboliza uma abertura. O quadro torna-se uma janela de entrada para o observador do passado e do presente, pois eterniza em sua composição as marcas da dinâmica de um universo de formação restrito e amplo nas trocas com o poder instituído.

Entendendo os quadros de formatura como uma coleção derivada de um trabalho de escolhas deliberadas que envolveram apreciações, avaliações, valores, intenções, esquecimentos, descartes ligados a um determinado imaginário pertencente a um determinado tempo e lugar pode-se inferir que a tentativa de reunir os fragmentos fotográficos em uma ordem lógica e aceitável é uma tentativa de alcançar um efeito de longa duração. Essa continuidade, ganha sentido na construção de uma narrativa de grupo ligado à formação docente, que compartilha os signos e códigos característicos da 
profissão. Uma unidade de fotografias individuais, interligadas por uma rede de sociabilidade e destacadas do todo pela transição perpetrada pelos limites da moldura.

A análise dos quadros de formatura do CCJ produzidos por Arthur Carmo e José Ruhland proporcionou a constatação de elos contraditórios: de um lado, a convivência entre a inovação fotográfica e a arte pictórica; do outro, a frustração das promessas republicanas diante do atraso da expansão da escolarização. Ao receberem a tarefa de registrar uma composição artística capaz dar visibilidade ao acontecimento da formatura, os artistas perenizaram entre as molduras as representações provenientes da dinâmica social da época. Os quadros demarcam, delimitam e celebram através dos contornos de seu suporte, um território, um espaço de distinção social, de inclusão e exclusão, pertença e exílio. A instituição divulgou através desses baluartes de êxito e excelência, a conclusão de todo um processo de formação feminina, religiosa e profissional e assim, acionou uma tradição.

Trata-se de uma coleção de artefatos imagéticos que pertencem à coleção de objetos do acervo do CCJ que compõem a cultura material escolar da instituição. Sua materialidade transcende a presença física, pois fizeram e fazem parte de uma trama de relações com seus produtores e consumidores que, em contato com eles, de alguma maneira deram sentido mútuo as suas existências no universo da escolar. Documentos e testemunhos de um momento de celebração, reconhecimento e consolidação, os quadros de formatura guardam em suas molduras fragmentos de uma escola pulsante, de saberes e práticas vividas, sentidas e reproduzidas. Compartilham essa condição com outras centenas de objetos, com os quais dividem o espaço do acervo no sótão. E, assim como os quadros de formatura e objetos de outras instituições, aguardam por quem lhes desperte do silêncio e do esquecimento. 


\section{Referências}

ABREU, Regina. A fabricação do imortal: memória, história e estratégias de consagração no Brasil. Rio de Janeiro: Rocco, 1996.

AUMONT, Jacques. A imagem. Campinas, São Paulo: Papirus, 1993.

BENJAMIN, Walter. A obra de arte na era de sua reprodutibilidade técnica. Obras escolhidas: Magia e técnica, arte e política. 6. ed. São Paulo: Brasiliense, 1994.

BORGES, Maria Eliza Linhares. História e fotografia. Belo Horizonte: Autêntica, 2003.

CHARTIER, Roger. O mundo como representação. Revista de estudos avançados. São Paulo, v. 5, n. 11, jan. / abr. 1991. Disponível em:

<http://www.scielo.br/scielo.php?pid=S0103-40141991000100010\&script=sci_arttext>. Acesso em: 19 de fev. 2012.

CUNHA, Maria Teresa Santos. Rezas, ginástica e letras: normalistas do Colégio Coração de Jesus. Florianópolis décadas de 1920 e 1930. In: DALLABRIDA, Norberto (org.). Mosaico de escolas. Modos de educação em Santa Catarina na Primeira República. Florianópolis: Cidade Futura, 2003.

CUNHA, Maria Teresa Santos. “Caríssimas afilhadas": imagens de professoras nos discursos de paraninfos (Florianópolis, 1945/61). [2012]. Disponível em: <

http://www.portalanpedsul.com.br/admin/uploads/2004/Painel/Painel/11_54_00_CARISSI MAS_AFILHADAS_IMAGENS_DE_PROFESSORAS_NOS_DISCURSOS_DE.pdf $>$ Acesso em $19 / 08 / 2012$.

DELORY-MOMBERGER, Christine. Álbuns de fotos de família, trabalho de memória e formação de si. In: VICENTINI, Paula Perin; ABRAHÃO, Maria Helena Menna Barreto (Orgs). Sentidos e potencialidades e usos da (auto)biografia. São Paulo: Cultura Acadêmica, 2010. p. 95-111.

FISCARELLI, Rosilene Batista de Oliveira. Vestígios da cultura material escolar: história e memória da escola pública inscrita em troféus e medalhas. In: CONGRESSO BRASILEIRO DE HISTÓRIA DA EDUCAÇÃO SBHE, IV de 05 a 08 de Novembro de 2006, Goiânia - GO. Comunicação coordenada e apresentada no congresso. Goiânia: Editor, 2006.

FREUND, Gisèle. La fotografia como documento social. Barcelona: Gustavo Gili. 2011.

JORNAL REPÚBLICA. Orgão do Partido Republicano Catharinense. Florianópolis, quintafeira, 5 de janeiro de 1922.

JORNAL REPÚBLICA. Orgão do Partido Republicano Catharinense. Florianópolis, domingo, 5 de fevereiro de 1922. 
JORNAL REPÚBLICA. Orgão do Partido Republicano Catharinense. Florianópolis, domingo, 2 de abril de 1922.

JORNAL REPÚBLICA. Orgão do Partido Republicano Catharinense. Florianópolis, segundafeira, 6 de novembro de 1927.

LEAL, Elizabeth Juchem Machado; CUNHA, Maria Teresa Santos. A educação da mulher: uma visão do cotidiano de um colégio religioso feminino. Santa Catarina, 1991. Relatório de pesquisa UFSC, $91 \mathrm{p}$.

MARINHO, Flavio. A presença da imagem e o seu resgate: da paisagem cotidiana para o instante da escolha. Dissertação (mestrado) - Universidade do Rio Grande do Sul. Programa de Pós Graduação em Artes Visuais, Porto Alegre, 2002.

MARTIN, Ramón Lopes. El utilaje escolar e la segunda mitade del siglo XX. In.: Escolano Benito, Augustin (Dir.). História ilustrada de la escuela en España: Dos siglos de perspectiva histórica. Madrid: Fundación Germán Sánchez Ruipérez, 2006.

MARTINEZ, Silvi Alícia; FAGUNDES, Pedro Hernesto. Um arquivo escolar e muitas memórias - o arquivo histórico do Liceu de Humanidades de Campos. Cadernos de História da Educação, Uberlândia, v. 9, n. 1, p. 239-249, jan. / jun. 2010. Disponível em: <http://www.seer.ufu.br/index.php/che/article/view/7462/4779> Acesso em 15 de nov. de 2012.

MARTIARENA, Angelita Maria; OLIVEIRA, Maria Augusta Martiarena de. Fotografias de Professoras: a memória da feminização do magistério em Pelotas, 1920 a 1960. Revista História, Imagem e Narrativas, Pelotas, RS, n. 13, out. 2011 Disponível em: < www.historiaimagem.com.br/edicao13outubro2011/fotoprof.pdf > Acesso em 15 de nov. de 2012.

MELO, Sônia Pinto de Albuquerque; ALVES, André Luís Conceição. Instituto de educação rui barbosa: Docência e práticas de leitura nas décadas de 60 e 70 do Século xx. In: COLÓQUIO INTERNACIONALEDUCAÇÃO E CONTEMPORANEIDADE, V, São Cristóvão, SE, 21 a 213 set. de 2011. Anais... Disponível em: <www.educonufs.com.br/vcoloquio/cdcoloquio/.../conteudo.htm> Acesso em 15 de nov. de 2012.

MIGNOT, Ana Carolina Venâncio. Baú de memórias, bastidores de histórias: o legado pioneiro de Armanda Alvaro Alberto. $1^{\mathrm{a}}$. ed. Bragança Paulista: Editora da Universidade de São Francisco, 2002. v. 1. 356 p.

MORAES, Carmen Sylvia Vidigal. O inventário do acervo da Escola Normal Carlos Gomes e suas contribuições ao trabalho escolar e à pesquisa histórica. In: MENEZES, Maria C. (Org.). Inventário histórico documental: Escola Normal de Campinas (1903-1976) de Escola Complementar a Instituto de Educação. Campinas:FE/UNICAMP, 2009. 
MOTA, André. Um médico em transformação: os álbuns de formatura nos anos 1960. Revista Interface, Botucatu, v.13, n.31 out. / dez. 2009. Disponível em:

<http://www.scielo.br/scielo.php?pid=\$141432832009000400022\&script=sci_arttext> Acesso em 15 de novembro de 2012.

MOTTA, Luiz Gonzaga. Imprensa e Poder. In: MOTTA, Luiz Gonzaga (org). Imprensa e poder. Brasília: Editora Universidade de Brasília, São Paulo: Imprensa Oficial do Estado, 2002.(Coleção Comunicação).

NÓVOA, António. O passado e o presente dos professores. In.: NÓVOA, António (Org.). Profissão professor. Porto: Porto Editora, 1991.

PORTO, Fernando; SANTOS, Tânia Cristina Franco. O rito e os emblemas na formatura das enfermeiras brasileiras no distrito federal (1924 - 1925). Escola Anna Nery Revista de Enfermagem, Rio de Janeiro, v. 13, n. 2, abr. / jun. 2009. Disponível em:<http://dx.doi.org/10.1590/S1414-81452009000200003> Acesso em 15 de nov. de 2011.

RIBEIO, Ivanir; SILVA, Vera Lucia Gaspar da. Das materialidades da escola: o uniforme escolar. Educação e Pesquisa, v. 38, n.03, jul. / Set 2012, p 575-587. Disponível em: <www.educacaoepesquisa.fe.usp.br/wp.../10/v.38-n.03-de-2012.pdf> Acesso em 15 de nov. 2012.

RIBEIRO, Neurilene Martins. Prefaciando uma escuta sensível. Revista entreideias: educação, cultura e sociedade, Salvador, BA, 2007. Disponível

em:<http://www.portalseer.ufba.br/index.php/rfaced/article/view/2870/2037> Acesso em 15 de nov. de 2012.

ROCHA, Angélica Pinho Martins; LIMA, Sandra Cristina Fagundes de. História da Educação Rural nas Imagens da Escola Rural de Cruzeiro dos Peixotos (Uberlândia 19331959). In: CONGRESSO BRASILEIRO DE HISTÓRIA DA EDUCAÇÃO, IV, 2006. Anais... Goiânia: Editora Vieira e Editora da UCG, 2006. p. 1-11.

SCHWARTZMAN, Simon, BOMENY, Helena Maria Bousquet, COSTA, Vanda Maria Ribeiro. Tempos de Capanema. $2^{\text {a }}$ ed. São Paulo: Paz e Terra; Rio de Janeiro: Fundação Getúlio Vargas, 2001, 388p.

SOUZA, Rosa Fátima de. História da cultura material escolar: um balanço inicial. In: BENCOSTA, Marcus Levy (Org.). Culturas escolares, saberes e práticas educativas: itinerários históricos. São Paulo: Cortez, 2007.

SOUSA Jane Bezerra de. Ginásio Estadual Picoense: implantação e consolidação de uma instituição escolar (1949 - 1953). JORNADA DO HISTEDEBR, IV, Campo Grande 2007. Disponível em:

<http://www.histedbr.fae.unicamp.br/acer_histedbr/jornada/jornada7/03trab-gtgt3.htm> Acesso em 15 de novembro de 2012. 
VEIGA, Cynthia Greive. Cultura material escolar no século XIX em Minas Gerais. In: CONGRESSO BRASILEIRO DE HISTÓRIA DA EDUCAÇÃO, 1. Anais... Rio de Janeiro: SBHE, 2000. 1 CD.

WERLE, Flavia Obino Corrêa. Ancorando quadros de formatura na história institucional. Disponível em: <http://www.anped.org.br/28/textos/GT02/GT02-322--Int.rtf>. Acesso em: 18 de jun. 2006 